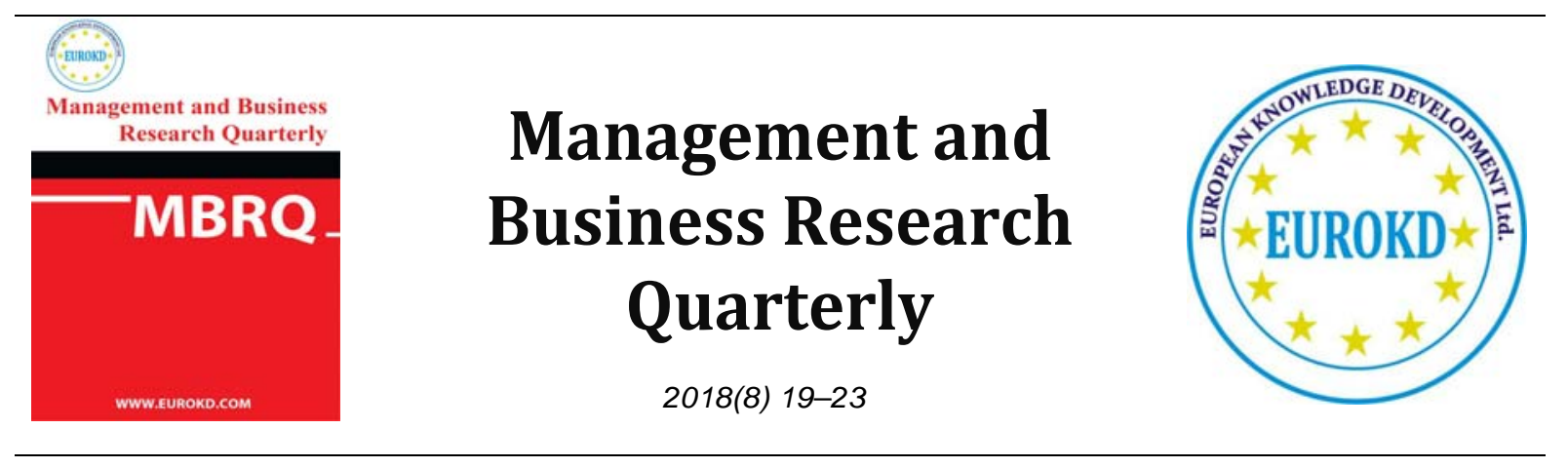

\title{
Exploring the Relationship between Self-awareness and Social Welfare
}

\author{
Robab Hazrati Kandeh*, Faranak Simanoor Ardabili \\ Department of Public Administration, Ardabil Branch, Islamic Azad University, Ardabil, Iran \\ Received 17 October 2018 Accepted 19 December 2018

\begin{abstract}
It is widely accepted that the concept and content of social welfare has changed substantially over the last few decades, and this variable can be affected by many factors. The purpose of the study was to investigate the relationship between self-awareness and social welfare. The study was a descriptive correlational study. The study population consisted of all citizens aged over 18 years old in Ardabil in 2018. According to the Cochran formula, 384 individuals were selected through a multistage random cluster sampling. To collect data, Fenigstein, Scheier, and Buss self-knowledge questionnaires and researcher-made social welfare questionnaire were used. The obtained data were analyzed by Pearson's tests, and simple and multiple regression. The results of the analysis showed a significant positive correlation between self-awareness dimensions (private selfawareness and public self-awareness) with social welfare. A reverse significant relationship was also observed between social anxiety and social welfare. The results suggest that private self-awareness more than other dimensions can predict social welfare changes.
\end{abstract} \\ ABSTRACT
}

Keywords: Self-awareness, Social Welfare, Private Self-awareness, Public Self-awareness

\section{Introduction}

Self-awareness or consciousness is one of the most important discussions of the mind philosophy and psychology. Along with the trend of social changes and the need for greater adaptability with the community, the need for self-awareness is felt more than ever. Self-awareness and self-efficacy are important in professional decision-making, as well as individual growth, and can flourish people's potentials. Organizations need to recognize these potentials in individuals in order to 
improve their capacities (Ferraris and Ozok, 2018). Many studies have shown that self-awareness skill plays a key role in social life of the people. General self-awareness increases social adjustment of individuals (Van Bommel et al., 2012) that in turn leads to more compatibility with community. Self-awareness facilitates the healthy process of identification for individuals and bestows peace to their life and increases their feeling of satisfaction. Activating general self-awareness improves peoples' association with the symbolic representation of their identity (White et al., 2018).

According to the research, self-awareness and its induction improves commitment to the social and moral norms and encourages people to act (Bander et al., 2018). Therefore, peoples' selfawareness is the most important guarantee of the implementation of citizenship rights. Society considers welfare of the human beings. In other word, when people play their contributory role appropriately and behave better, certainly the society gives them the rewards they deserve for playing these roles and behaviors. Self-awareness is a pre-requisite for ethical action, exercise and having access to work ethic through awareness (Fawkes, 2015). Therefore, half of social welfare is in inducing a social welfare mindset in people. In order to improve social welfare in society, we can take fundamental steps. One of these steps is to offer options in terms of how people can use products and services as a means to improve their social welfare (Botto, 2006). Also, good and informed selections need high levels of self-awareness. Social welfare leads to maximum profit and benefit for humans. According to the research, there is a relatively low difference between maximal profit and maximization of social welfare systems in terms of social welfare (Binjaafar et al., 2018). The peoples' enjoyment of high self-awareness will increase the quality of their life.

If people have a high level of self-awareness, they can adapt themselves better with the community and play an effective role in it, e.g. by paying taxes on time, and thus improve their social welfare. To discover innovative social opportunities has been suggested to increase interaction and cooperation between different sectors for social welfare (Dromantiene, 2018). On the contrary, the people with low self-awareness will deprive themselves. According to the research on deprivation manner, the countdown is related to the social-based approaches (Atkinson, 2003). Therefore, in order to avoid deprivation and lack of social welfare, it is necessary to educate and prepare people in terms of self-awareness and self-confidence. The findings of the study can be a guideline for organizations to improve insufficiencies of the community such as dissatisfaction, low self-esteem, low social welfare, poverty and inequality, and strengthen the solid foundation regarding the people in organizations and society through increasing self-awareness and selfconfidence in individuals.

\section{Methods}

Method: Given the purposes of the study, a fundamental method was adopted. A descriptivecorrelational data collection method was also used for the study, in which the structural relationships between variables were investigated.

Statistical population, sample size and sampling method: The statistical population of the study includes all citizens aged 18 years and over in Ardabil in 2018. Using Cochran formula, 384 people were selected through a multi-stage cluster randomized sampling method. 
Data collection method: The field method was used to collect required data. To that end, the questionnaires were handed out to the citizens. Finally, the questionnaires were gathered and the data was analyzed.

Data collection tool: Data collection tools used for the purpose of the study include:

Self-awareness questionnaire: This scale was developed and normalized by Fenigstein, Scheier, and Buss in 1975 to measure three distinct trends of self-awareness. The questionnaire includes 23 items. A 5-point Likert scale was devised to respond to the items that includes three components of private self-awareness, general self-awareness and social anxiety.

Social Welfare Questionnaire: To measure this variable, a researcher-made questionnaire of 15 questions with an interval scale was used.

Validity and reliability of the questionnaires were confirmed by content validity (formal) as well as Cronbach's alpha test.

Data analysis method: frequency was used to analyze the data, percentage was used to show demographic characteristics of students, the mean and standard deviation were used for descriptive statistics, and Pearson and regression tests were used for analyzing the hypotheses.

\section{Results}

According to the results of data analysis, there was a significant positive correlation between selfawareness and social welfare and the correlation coefficient between the two variables was equal to 0.58 . There was also a significant positive correlation between self-awareness and social welfare dimensions. Correlation coefficients between social welfare and private self-awareness, general self-awareness, and social anxiety are $0.56,0.41$ and -0.51 , respectively.

Table 1. Descriptive results and Pearson correlation coefficients for determining the correlation between self-awareness dimensions and social welfare

\begin{tabular}{llccc}
\hline Self-awareness dimensions & \multicolumn{1}{c}{ Statistics } & Social welfare & Mean & Cronbach's alpha \\
\hline Private self-awareness & Pearson Correlation Coefficient & $0.569^{* *}$ & 3.55 & 0.80 \\
\hline General self-awareness & Pearson Correlation Coefficient & $0.419^{* *}$ & 3.01 & 0.77 \\
\hline social anxiety & Pearson Correlation Coefficient & $-0.509^{* *}$ & 2.94 & 0.86 \\
\hline Self-awareness (total) & Pearson Correlation Coefficient & $0.582^{* *}$ & 3.55 & 0.91 \\
\hline
\end{tabular}

According to the results of Table (1) and given that the significance level of the test error for the confidence level of 0.99 is less than 0.01 , it can be said that there is a significant relationship between self-awareness and social welfare dimensions. The correlation coefficients between social welfare and private self-awareness, general self-awareness, and social anxiety were $0.56,0.41$ and -0.51 , respectively. The mean of private self-awareness, general self-awareness, social anxiety, and self-awareness (total) were 3.01, 2.94, and 3.55, respectively. 
Given the previous hypotheses, multiple regression test was used to determine the effect of selfawareness and social welfare dimensions. This test shows the predictive value of the variations of dependent variable.

Table 2. A summary of regression model between dimensions of self-awareness and social welfare

\begin{tabular}{ccc}
\hline correlation coefficient & Coefficient of Determination & Adjusted Coefficient of Determination \\
\hline 0.67 & 0.44 & 0.44 \\
\hline
\end{tabular}

According to the results of Table 2, the correlation coefficient between dimensions of selfawareness and social welfare is 0.67 and the coefficient of determination is 0.44 . Accordingly, the dependent variable determines social welfare and the rest is related to other variables.

Table 3. The results of multiple regression analysis between dimensions of self-awareness and social welfare

\begin{tabular}{lccccc}
\hline \multirow{2}{*}{ Items } & \multicolumn{2}{c}{ Non-standard coefficients } & \multirow{2}{*}{ standardized beta coefficient } & \multirow{2}{*}{ S } & \multirow{2}{*}{ Sig. } \\
\cline { 2 - 3 } & $\mathrm{B}$ & $\mathrm{SD}$ & & 23.12 & 0.000 \\
\hline Constant value & 1.399 & 0.061 & 0.58 & 10.84 & 0.000 \\
\hline Private self-awareness & 0.336 & 0.031 & 0.55 & 10.15 & 0.000 \\
\hline General self-awareness & 0.196 & 0.019 & -0.170 & 2.77 & 0.006 \\
\hline Social anxiety & 0.132 & 0.047 & & &
\end{tabular}

In order to determine the effect of self-awareness dimensions (private self-awareness, public self-awareness and social anxiety) as a predictor variable and social welfare as a criterion variable, multiple regression analyzes with enter method was performed. As it can be seen from Table 3, the $\mathrm{p}$ value observed in these variables is significant, and the results show that the private selfawareness variable with the highest rate $(\mathrm{BETA}=0.58)$, and general self-awareness $(\mathrm{BETA}=0.55)$ and social anxiety with the lowest rate $(\mathrm{BETA}=-0.17)$ predict social welfare variable.

\section{Discussion and Conclusion}

Social welfare is an interpretation of economic, social and political situation that targets the maintenance of human dignity and the accountability of the community members against each other and the improvement of capabilities. As theoretical foundations and previous studies show, the dominant discourse of social welfare until recent decades and before emergence of "cultural turn" in social theory in the 1970s, has been "material discourse" and only these material, quantitative, objective, measurable, and economic categories have been considered as factors creating or preventing social welfare of the societies or specific social groups. The fundamental transformation in the social welfare discourse began first in the 1970s, when economy-driven development theories faced social and cultural challenges, and especially the approaches to "modernization theory" could not help development of the Third World countries, and "dependency theory", whose main describer was Andre Gonder Frank, and the "world system theory", whose main describer was Wallerstein, and "critical feminist theories" and "neo-marxist theories" of the Frankfurt School and the Birmingham School of Cultural Studies, strongly challenged the validity of modernization theory and economy-driven approaches. The indices considered for social welfare in Iran include 
education, health, healthcare, nutrition, housing, employment and manpower, social security costs and income (Zahedi Asl, 2011). In addition to the main indices, several sub-indicators are also considered for welfare, such as spending leisure time, access to cultural facilities, the environment, and individual security against financial and psychological aggression.

To solve or control social issues; although there is no consensus on the meaning and content of what is called social affairs, there is a general agreement on issues such as unemployment, violence, drug use, poverty, suicide and theft. Demand supply; this concept has also evolved substantially during past decades, and besides dimensions such as biological needs, housing, education, health includes other needs that are essential for a society's logical and appropriate living. Ensuring equal social opportunities; this concept means equal opportunities in terms of occupation, education and social promotion, regardless of individual situations. In case of inequality of opportunity, individuals will resort to unfair and unreasonable methods to meet their needs. This problem ultimately leads to the expansion of the first area, i.e. social issues. Given the above and considering the results of hypotheses analysis, the study shows a significant positive correlation between selfawareness dimensions (including private awareness and public self-awareness) with social welfare, and a negative significant relationship between social anxiety and social welfare. The predictions also show that self-awareness more than other dimensions can predict the changes related to social welfare.

\section{References}

Atkinson, A. B. (2003). Multidimensional deprivation: contrasting social welfare and counting approaches. The Journal of Economic Inequality, 1(1), 51-65.

Bender, J., O'Connor, A. M., \& Evans, A. D. (2018). Mirror, mirror on the wall: Increasing young children's honesty through inducing self-awareness. Journal of experimental child psychology, 167, 414-422.

Benjaafar, S., Kong, G., Li, X., \& Courcoubetis, C. (2018). Peer-to-peer product sharing: Implications for ownership, usage, and social welfare in the sharing economy. Management Science, 65(2), 477-493.".

Botti, S., \& Iyengar, S. S. (2006). The dark side of choice: When choice impairs social welfare. Journal of Public Policy \& Marketing, 25(1), 24-38.

Delton, A. W., Petersen, M. B., DeScioli, P., \& Robertson, T. E. (2018). Need, compassion, and support for social welfare. Political Psychology, 39(4), 907-924.

Dromantienè, L., Štaras, K., \& Ūselytė, M. (2018). The role of cultural involvement of patients for their social welfare. In SHS web of conferences: proceedings: 6th international interdisciplinary scientific conference, Society. Health. Welfare ": November 2325, 2016 Riga, Latvia (Vol. 3007, pp. 1-10). EDP Sciences..

Fawkes, J. (2015). A Jungian conscience: Self-awareness for public relations practice. Public Relations Review, 41(5), 726-733.

Fenigstein, A., Scheier, R. M. F., \& Buss, A. H. (1975). Public and private- self-consciousness: assessment and theory. Journal of Consulting and Clinical Psychology, 43(4), 522-527.

Özek, H., \& Ferraris, A. (2018). The Role of Self-Awareness and Self-Efficacy on Career Decision-Making: An Innovative Perspective. In Innovation and Capacity Building (pp. 207-229). Palgrave Macmillan,Cham.

Van Bommel, M., van Prooijen, J. W., Elffers, H., \& Van Lange, P. A. (2012). Be aware to care: Public self-awareness leads to a reversal of the bystander effect. Journal of Experimental Social Psychology, 48(4), 926-930.

Zahedi Asl, M. (2011). The Basics of Social Welfare, Fourth Edition, Tehran: Allameh Tabataba'i University Press. 